\title{
Histological and Histochemical Vascular Changes in Experimentally Induced Diabetic Rats
}

\author{
Ahmed El-kassaby; El-Sayed G. Khedr; Abdelmawgood A. ; \\ Mamdooh Ghaly; Atef I. and Moustafa El-Sawy \\ Department of Histology; Faculty of Medicine; Al-Azhar University; Cairo
}

\begin{abstract}
In this study, induction of diabetes in adult male albino rats by subcutaneous injection of alloxan was done, to evaluate its effects on some blood vessels (Aorta,Femoral and Renal arteries). Thirty adult male albino rats were divided into two groups, diabetic group, and control group, fifteen animals each. After 6 weeks rats were operated and paraffin as well as frozen sections of samples from the Aorta, Femoral and Renal arteries were prepared and stained with different histological and histochemical stains. Histological examination and statistical evaluation of the aorta of diabetic group has showed marked intimal thickening caused by infiltration of smooth muscles, which appear vacuolated. Moreover, the subintimal layer of the media has showed marked proliferation of smooth muscles, with thickened, fragmented elastic fibers, and increased collagen content. The mean ratio of the total areas occupied by collagen fibers was $18.5 \pm 1.6$, and that of the smooth muscles was $19.8 \pm 1.0$ in the media. That in turn was significantly increased $(\mathrm{P}<0.01)$ when compared to the control group $(8.1 \pm 1.0)$ and (12.9 \pm 0.9$)$ respectively. Also, the mean thickness of the adventitia was $258.8 \pm 4.0$, and the mean number of fibroblasts was $41.5 \pm 1.7$, was significantly higher than those in the control group $(\mathrm{P}<0.01)$, which were $185.4 \pm 3.4$ and $13.1 \pm 1.3$ respectively. Histochemical results have showed presence of fatty material in the intima and media. Also, the mean optical density (O.D.) values of PAS positive materials was $(0.36 \pm 0.01)$, which was significantly increased $(\mathrm{P}<0.01)$ than that of the control group $(0.32 \pm 0.01)$. Similar results have been also detected in the femoral artery. Furthermore, the renal artery has showed thickening and fragmentation of the external elastic lamina. In conclusion, diabetes has a damaging effect on blood vessels leading to impairment of their functions .
\end{abstract}

\section{Introduction}

Diabetes mellitus is a common metabolic disease characterized a variety of microvascular, macrovascular and neurologic complications. It is not a single disease but it is a heterogeneous group of disorders related to each other (Silvio, 2003). The prevalence of the disease is increasing globally. It is estimated that in 2000 there were approximately 150 million individuals with the disease and that this number is likely to double by 2025 (King, et al., 2002). Diabetes mellitus is a major risk factor seem to contribute to the development of atherosclerosis (Ross, 1999)and patients die more commonly 
from macrovascular diseases (Dowens, et al., 1998). The disease progresses slowly throughout adult life and the causal factors exert their effects over a long period, (Roderick, \& Keith 2001). The close metabolic links between microvascular and macrovascular diseases and other contributing factors such as; lipoprotein oxidation, advanced glycosylation end products (AGEs), glucotoxicity monocyte and $\backslash$ ormacrop hage function, immune mechanism, and abnormalities in connective tissue matrix are responsible for premature atherosclerosis in diabetic patients (Danial, 2003). With the development of cell culture techniques and microsc opic methods for identification of endo thelial cells many studies have been carried out to determine the nature of atherosclerosis in diabetic subjects, which could shed some light on the reason for the excess morbidity from atherosclerosis in such persons. (Sternby, 1968). Migration and prolifer ation of smooth muscle cells from the media to the intima and increase in collagen synthesis in diabetic blood vessels had been reported by Poulter, (1999) and Askari, et al., (2002). Also, fragmentation of elastic fibers in the aorta of diabetic rats had been reported by and(Uemura, et al., 2001).Moreover, Roderick, \& Keith (2001) reported the accumolation of lipids in lipid laden cells in the intima of diabetic vessels. The present study was designed to induce diabetes in adult male albino rats and to evaluate the concomitant vascular changes in the aorta, femoral, and renal arteries .

\section{Material and methods}

Thirty adult male albino rats 12 weeks old, weighting 140-150 mg. were raised on the ordinary diet for 6 weeks. The animals were divided into two groups; diabetic and a control; each of fifteen animals; The diabetic group was injected subcutaneously by alloxan dissolved in Acetate buffer at a dose $100 \mathrm{mg} / \mathrm{kg}$ body weight while the control group was subcutaneously injected by the same dose of acetate buffer solution. Repeated blood samples from both groups throughout the experiment were tested for glucose and the state of indued diabetes was followed up. Rats representing the different groups were anaesthetised and the aorta, the renal, and the femoral arteries were perfused with neutral formol saline for in situ fixation then carefully dissected. Each specimen was prepared for (8um) frozen and(6um) paraffin sections. Sections of the control and diabetic groups of each blood vessels were mounted on the same slide and stained with Haematoxylin and Eosin; Masson trichrome; Mallory triple stain; Periodic Acid Schiff technique (P.A.S.) and orcein. Frozen sections were stained by osmic tetraoxide. Stained sections were subjected for quantitative analysis using the computerized image analyzer.

\section{Results}

Stained sections in the aorta of diabetic group with Hx. and E showed marked intimal thickening while the lining endothelial cells were not intact. The tunica media showed increased connective tissue in some areas where the muscle and elastic fibers were pressed towards the intima, Plate1 (C\&D). The mean number of fibroblasts in the adventitia of diabetic group was $(41.5 \pm 1.7)$ which was significantly increased $(\mathrm{P}<0.01)$ than that of the control group (13.1 \pm 1.3$)$.Table(1 ) In Masson trichrome stained sections collagenous fibers and smooth muscle cells are increased in the subintima (adluminal layers of the media) . Some smooth muscle cells showed buffing 
and vacuolation (foam cells), Plate1(A\&B). The mean ratio of the total areas occupied by collagen fibers in the media of diabetic group was $(18.5 \pm 1.6)$ which was significantly increased $(\mathrm{P}<0.01)$ than that of the control group $(8.1 \pm 1.0)$, Table (2),Plate1(E\&F). Also the mean ratio of the total areas occupied by smooth muscle fibers in the media of diabetic group was $(19.8 \pm 1.0)$ which was significantly increased $(\mathrm{P}<0.01)$ than that of the control group $(12.9 \pm 0.9)$. Table (3), Plate1 (A\&B). The mean thickness of tunica adventitia was $(258.8 \pm 4.0)$ which was significantly increased $(\mathrm{P}<0.01)$ than that of the control group (185.4 \pm 3.4$)$ Table (5) In Orcein stained sections thickening and fragmentation of some elastic fibers were seen in the media.Plate2(A\&B). In Osmic tetra oxide stained sections black stained areas were seen in the intima and media of the aorta of diabetic group indicating the presence of fatty material which were absent in control group,Plate2(E\&F). In P.A.S stained section the mean optical density of glycosaminoglycans in the aorta of diabetic group was $(0.36 \pm 0.01)$ which was significantly increased $(\mathrm{P}<0.01)$ than that of the control $(0.32 \pm 0.01)$. Table 6; Plate2 (C\&D).

Stained sections of the femoral arteries of the diabetic group showed intimal thickening. the endothelial cells of the intima were not intact. The subendothelial connective tissue layer was infiltrated in some areas by smooth muscle cells Plate3(C\&D). Areas of irregular thickening and fragmentation of elastic fibers were seen in the media. Plate3(E\&F). Buffing and vacuolation of smooth muscle cells (foam cells) were seen in some areas of the media.Plate3(C\&D) The amount of connective tissues in the media was increased. The adventitial layer was more thicker thanin the control. Plate4(A\&B). In orcein stained sections of renal artery, the only microscopic change was thickening with slight fragmentation of the internal and external elastic laminae Plate5 (C\&D). Otherwise,no clear morphological changes were seen in the renal artery of diabetic group.

\begin{tabular}{|c|c|c|}
\hline & Control & Diabetic \\
\hline Mean & 13.17 & 41.58 \\
\hline S.D & 1.39 & 1.78 \\
\hline S.E & 0.57 & 0.73 \\
\hline T.value & \multicolumn{2}{|c|}{ Co.01 } \\
\hline P.value & \multicolumn{3}{|c|}{ High Significant } \\
\hline Significance & \multicolumn{3}{|c|}{} \\
\hline
\end{tabular}

Table (1): The number of fibroblasts in the aortic adventitia of control and diabetic rats.

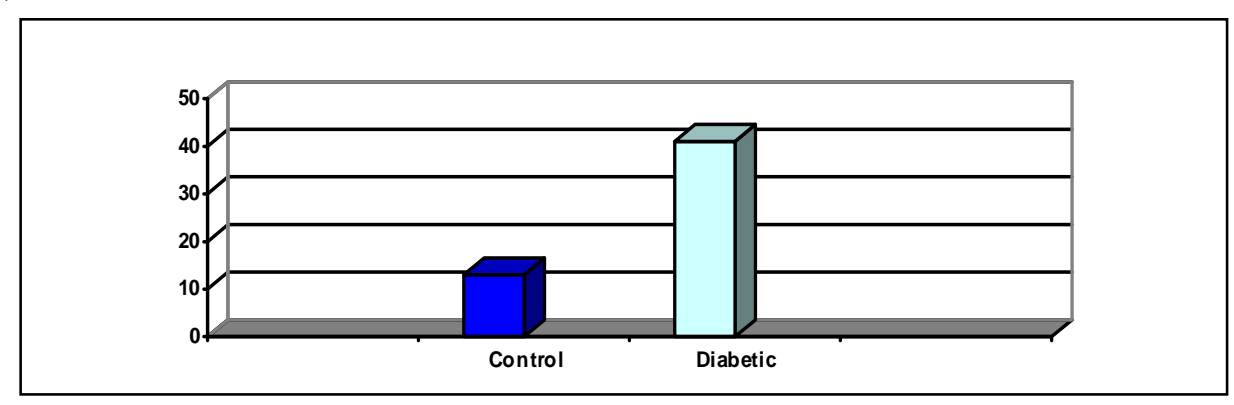

Figure (1): The mean number of fibroblasts in the aortic adventitia of control and diabetic rats. 
Ahmed El-kassaby et al

\begin{tabular}{|c|c|c|}
\hline & Control & Diabetic \\
\hline Mean & $\mathbf{8 . 1 2}$ & 18.55 \\
\hline S.D & 1.05 & 1.60 \\
\hline S.E & $\mathbf{0 . 4 3}$ & $\mathbf{0 . 6 5}$ \\
\hline T. value & \multicolumn{2}{|c|}{13.4} \\
\hline P.value & \multicolumn{2}{|c|}{ High Significant } \\
\hline Significance & \multicolumn{2}{|c}{. } \\
\hline
\end{tabular}

Table (2): the total area occupied by collagen fibers in the aorta of control and diabetic rats.

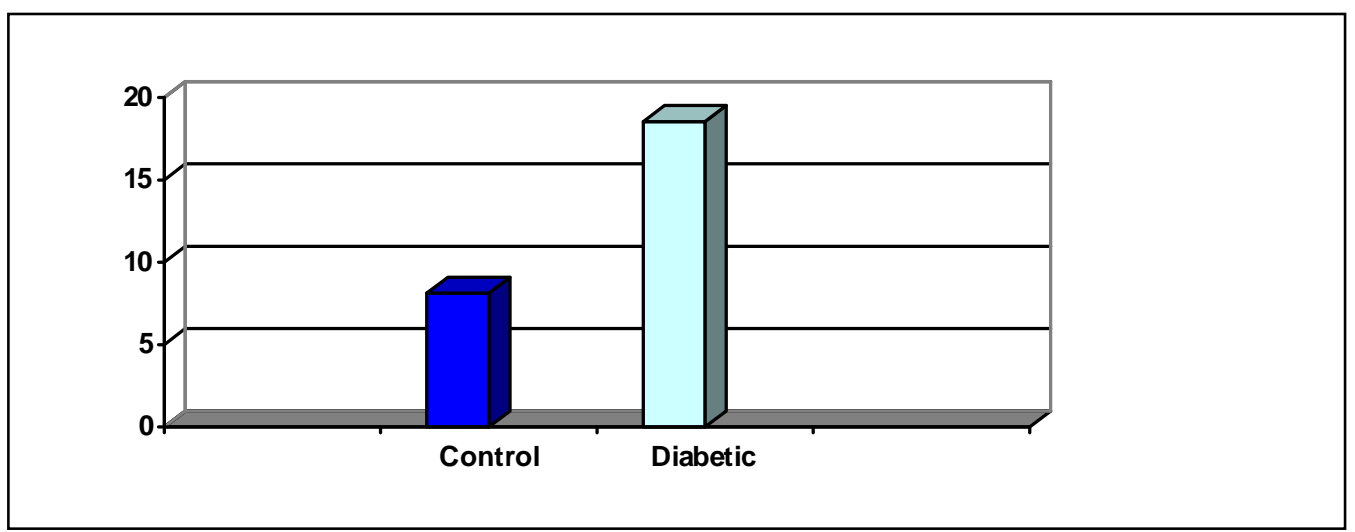

Figure (2): The mean ratio of the total area occupied by collagen fibers in the aorta of control and diabetic rats.

\begin{tabular}{|c|c|c|}
\hline & Control & Diabetic \\
\hline Mean & 12.94 & 19.86 \\
\hline S.D & $\mathbf{0 . 9 8}$ & $\mathbf{1 . 0 5}$ \\
\hline S.E & $\mathbf{0 . 4 0} 0.34$ \\
\hline T.value & \multicolumn{2}{|c|}{30.3} \\
\hline P.value & \multicolumn{2}{|c|}{ High Significant } \\
\hline Significance & \multicolumn{3}{|c|}{} \\
\hline
\end{tabular}

Table (3): The total area occupied by smooth muscle fibers in the aorta of control and diabetic rats.

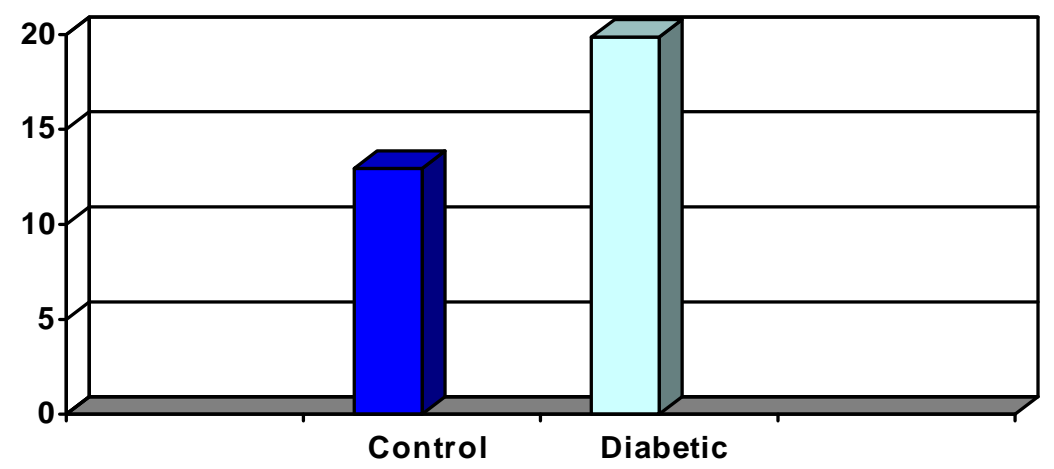

Figure (3): The mean ratio of the total area occupied by smooth muscle fibers in the aorta of control and diabetic rats. 
Histological and Histochemical Vascular Changes.........

\begin{tabular}{|c|c|c|}
\hline & Control & Diabetic \\
\hline Mean & 183.88 & 237.17 \\
\hline S.D & 2.30 & 1.74 \\
\hline S.E & 0.94 & 0.71 \\
\hline T.value & \multicolumn{2}{|c|}{45.3} \\
\hline p.value & \multicolumn{2}{|c|}{ High Significant } \\
\hline Significance & \multicolumn{2}{|c|}{} \\
\hline
\end{tabular}

Table (4): Mean thickness of the media in the aorta of control and diabetic rats

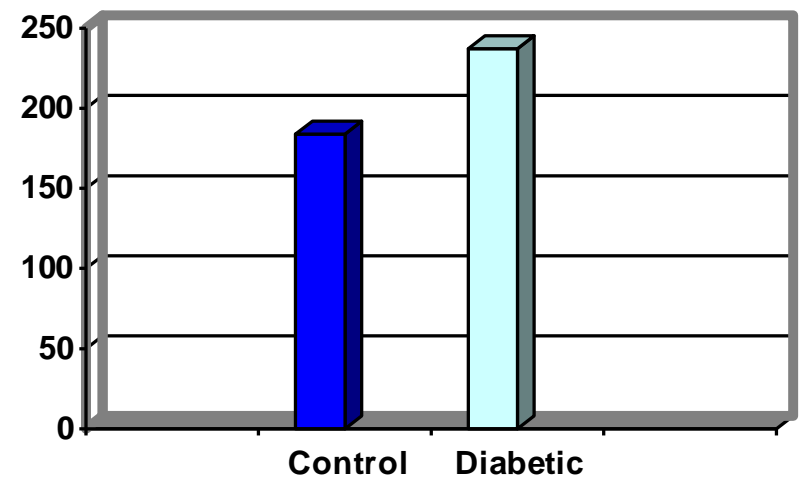

Figure (4): The mean thickness of the aortic media of control and diabetic rats.

\begin{tabular}{|c|c|c|}
\hline & Control & Diabetic \\
\hline Mean & 185.45 & 254.81 \\
\hline S.d & 3.43 & 4.05 \\
\hline S.E & 1.40 & 1.65 \\
\hline T.value & \multicolumn{2}{|c|}{78.5} \\
\hline P.value & \multicolumn{2}{|c|}{$<0.01$} \\
\hline Significance & \multicolumn{2}{|c|}{ High Significant } \\
\hline
\end{tabular}

Table (5): The mean adventitial thickness in aorta of control and diabetic rats.

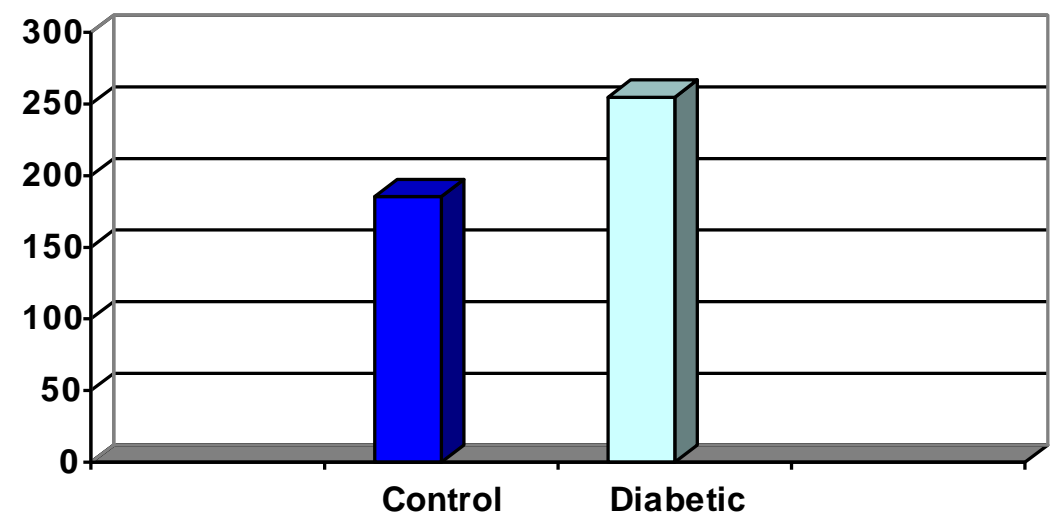

Figure (5): The mean thickness of the aortic adventitia of control and diabetic rats. 
Ahmed El-kassaby et al

\begin{tabular}{|c|c|c|}
\hline & Control & Diabetic \\
\hline Mean & 0.32 & 0.36 \\
\hline S.D & 0.01 & 0.01 \\
\hline S.E & 0.000 & 0.00 \\
\hline T.value & \multicolumn{2}{|c|}{6.93} \\
\hline P.value & $<0.01$ \\
\hline Significance & \multicolumn{2}{|c|}{ High Significant } \\
\hline
\end{tabular}

Table (6): Quantitative results of the mean optical density values of glycosaminoglycans content in the aorta of control and diabetic rats.

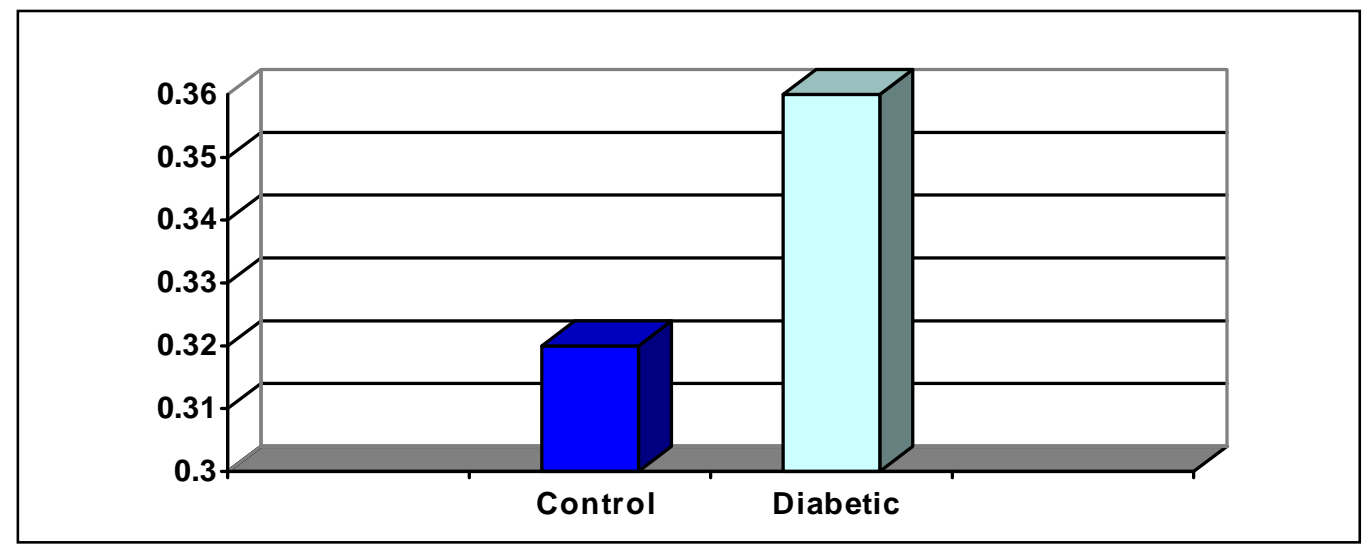

Figure (6): The mean optical density values of glycosaminoglycans content in the aorta of control and diabetic rats.

PLATE 1 :

A-Photomicrograph in the aorta of diabetic group showing accumulation of collagen fibers and smooth muscle cells in the subintima. The smooth muscles and collagen fibers were increased in the media compared to that of control group. (Masson trichrome $\mathrm{x} 400$ ).

B-Photomicrograph in the aorta of control group showing wavy elastic and collagen fibers with smooth muscle cells distributed in between in tunica media. (Masson trichrome x 400) C-Photomicrograph in the aorta of diabetic group showing disorganized pattern of tunica intima and the adjacent tunica media. The intima is wide and shows irregular smooth muscles with some vacuolated spots of dissolved fat.

(Hematoxylin \& Eosin x 400)

D-Photomicrograph in the aorta of control group showing intact endoth elium, thin subendothelial layer and apparent wavy elastic fibers
(Hematoxylin \& Eosin x 400)

E-Photomicrograph in the aorta of control group showing regular arrangement of connective tissue fibers in the tunica intima and tunica media. (Mallory Triple x 200)

F-Photomicrograph of the aorta of diabetic group showing marked distur bance in the regularity of connective tissue. Both the media and the adven titia are apparantly thicker than in the control group (Mallory Triple x200)

\section{PLATE2:}

A-Photomicrograph of the aorta of diabetic group showing irregular less formed elastic fibers in both tunica intima and tunica media. (Orcein x 400) B-Photomicrograph of the aorta of control group showing wavy, corrug ated internal elastic membrane with a well organized wavy elastic fibers in tunica media (Orcein x 400) C-Photomicrograph of the aorta of 
diabetic group showing increased PAS positive material in the tunica media compared to the control group. (PAS x 200)

D-Photomicrograph of the aorta of control group showing stained PAS positive material ( glycosaminoglycans) in the matrix of bath tunica intima and tunica media. (PAS x 200)

E-Photomicrograph of the aorta of diabetic group showing osmic stained fatty material in both tunica intima and tunica media. (Osmic tetraoxide x200) F-Photomicrograph of the aorta of control group showing adventitial fat cells stained black with osmic acid.

(Osmic tetra oxide x 200)

\section{PLATE 3 :}

A-Photomicrograph of the femoral artery of diabetic group showing disorganized pattern of both tunica intima and tunica media. The components of the media are diffused and replaced by amorphous matrix. (Hematoxylin \& Eosin x 200)

B-Photomicrograph of the femoral artery of control group showing intact endothelium, thin subendothelial layer and apparent wavy internal elastic membrane(Hematoxylin \& Eosin x 200) C- Photomicrograph of the femoral artery of diabetic group showing accumulation of collagen fibers and smooth muscle cells in the subintima leading to bulging and tearing of the endothelium (Masson trichrome x 200). D-Photomicrograph of the femoral artery of control group showing wavy elastic and collagen fibers and smooth muscle cells, in tunica media. (Masson trichrome x 200)

E-Photomicrograph of the femoral artery of diabetic group showing diffused less formed elastic membranes in both tunica intima and tunica media. (Orcein x 200)
F-Photomicrograph of the femoral artery of control group showing wavy, corrugated internal elastic membrane with normal organized wavy membr anes in tunica media. (Orcein x 200)

\section{PLATE 4 :}

A-Photomicrograph of the femoral artery of diabetic group showing marked disturbance in the regularity of connective tissue ( Mallory triple x 200) B-Photomicrograph of the femoral artery of control group showing regular arrangement of connective tissue fibers in the tunica intima and tunica media.

$$
\text { (Mallory triple x 200) }
$$

C-Photomicrograph of the femoral artery of diabetic group showing the increased PAS positive material in the tunica media compared to the control group (PAS x 200)

D-Photomicrograph of the femoral artery of control group showing PAS positive material (glycosaminoglycans) in the matrix of bath tunica intima and tunica media (PAS x 200)

E-Photomicrograph of the renal artery of diabetic group showing diffused less apparent internal elastic lamina.

(Hematoxylin \& Eosin x 200)

F-Photomicrograph of the renal artery of control group showing intact flattened endothelium and corrugated internal elastic membrane which rest on the smooth muscle cells .

(Hematoxylin \& Eosin x 200)

\section{PLATE 5 :}

A-Photomicrograph of the renal artery of control group showing wavy collagen fibers in the tunica media and thin tunica adventitia.

(Masson trichrome $\mathrm{x} 400$ )

B-Photomicrograph of the renal artery of diabetic group showing that tunica adventitia is thicker than that of the control. (Masson trichrome x 400). 
C-Photomicrograph of renal artery of control group showing wavy intact internal and external elastic membranes with well organized elastic fibers in the tunica media. (Orcein x 200).

D-Photomicrograph of renal artery of diabetic group showing less intact elastic fibers in the tunica media. (Orcein x 200).
E-Photomicrograph of the renal artery of control group showing deposition of PAS positive material (glycosaminogl ycans) in the matrix of both tunica intima and tunica media. (PAS x 200) F-Photomicrograph of the renal artery of diabetic group showing the increased PAS positive material in the tunica media compared to controlgroup. (PAS x 200)

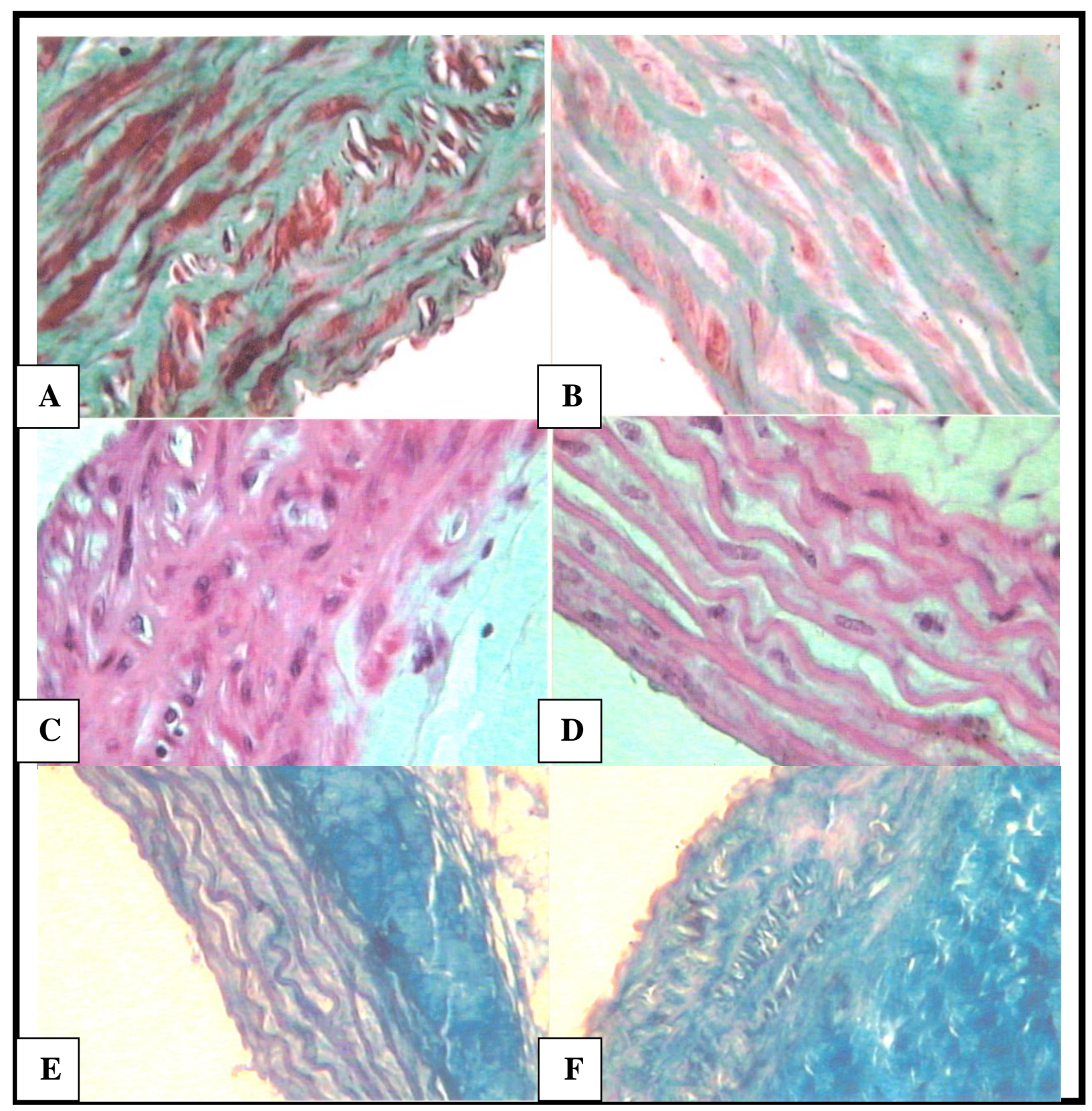

Plate 1 
Histological and Histochemical Vascular Changes.........

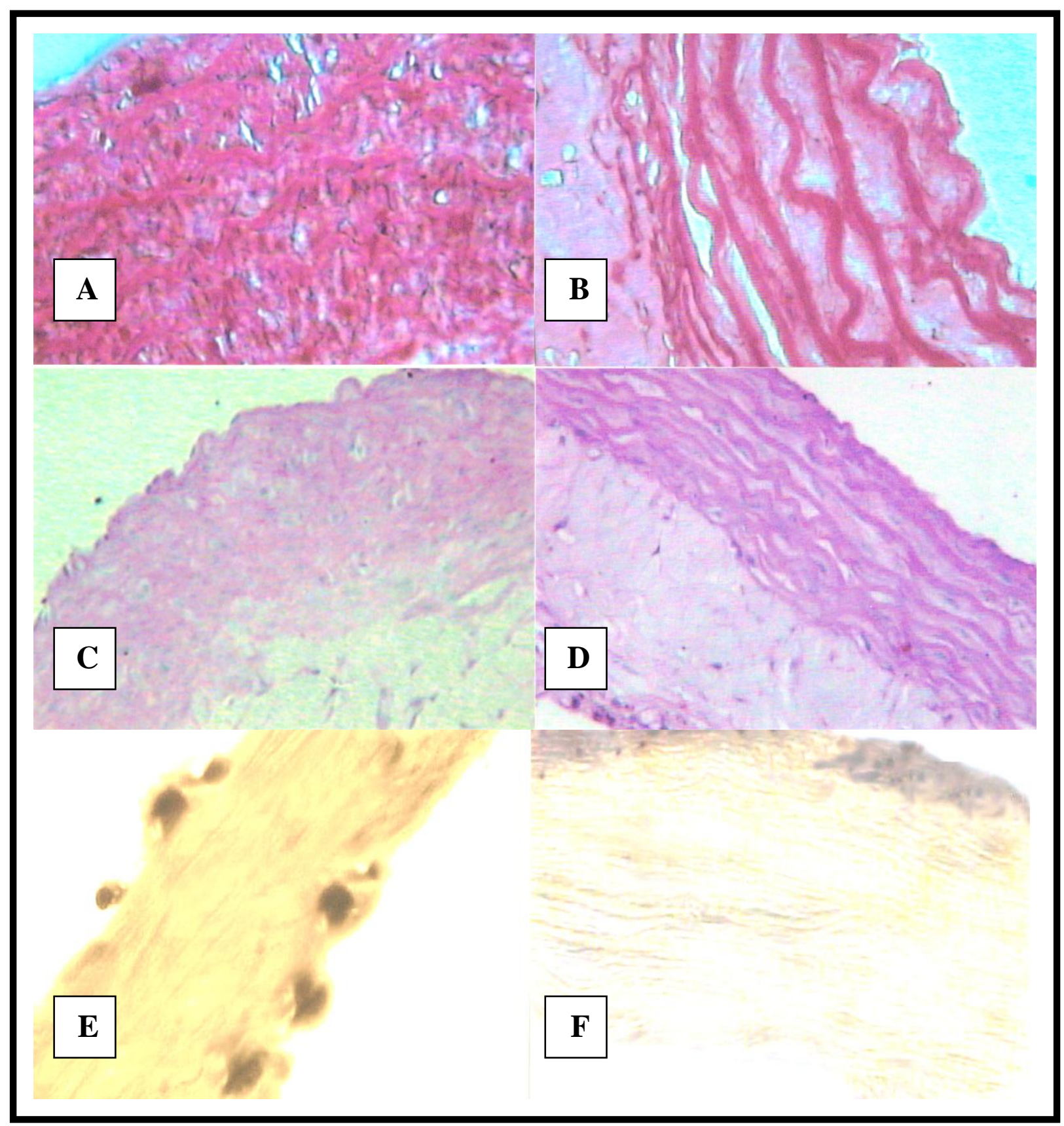

Plate 2 
Ahmed El-kassaby $\boldsymbol{e t}$ al

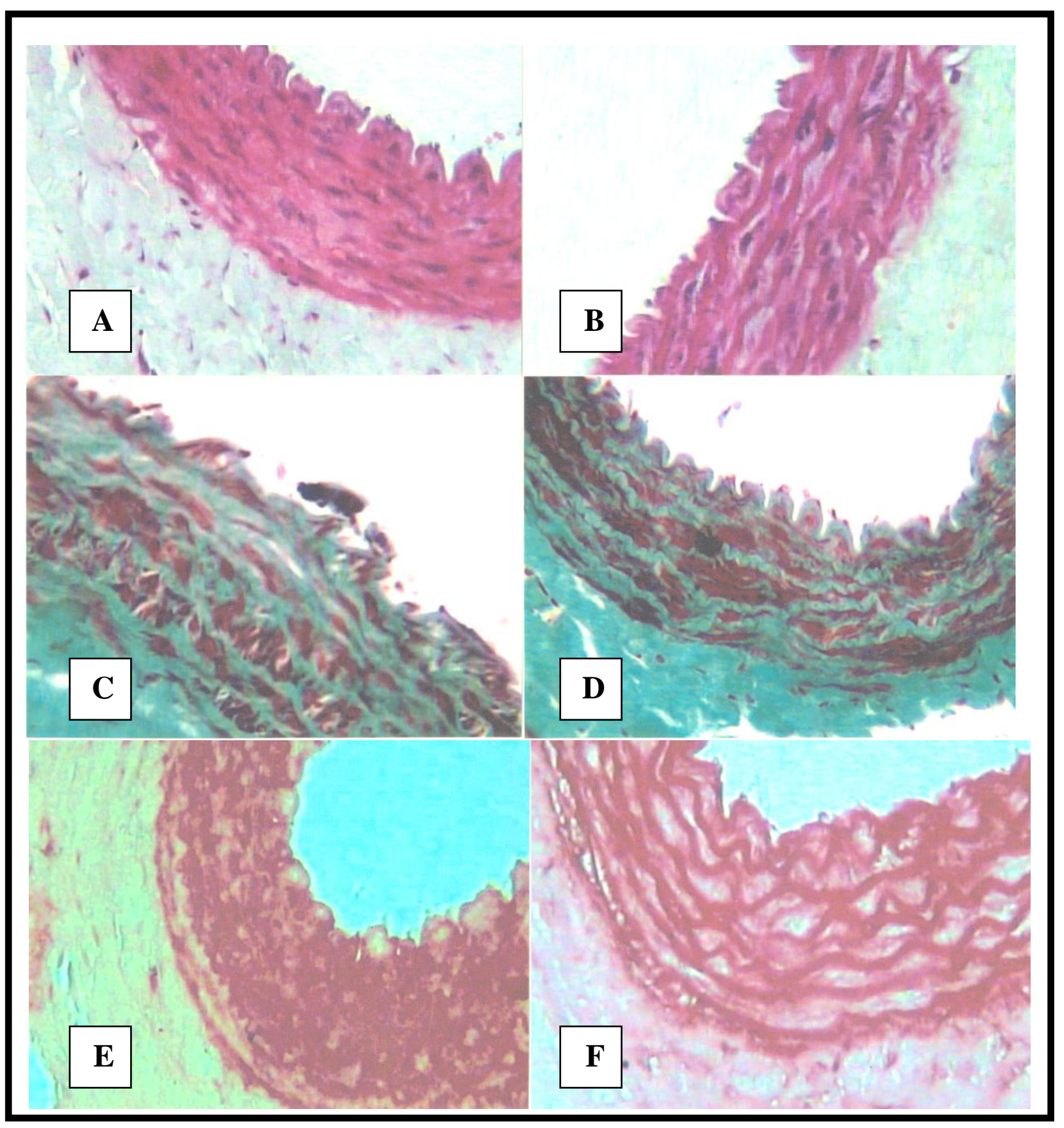

Plate 3 


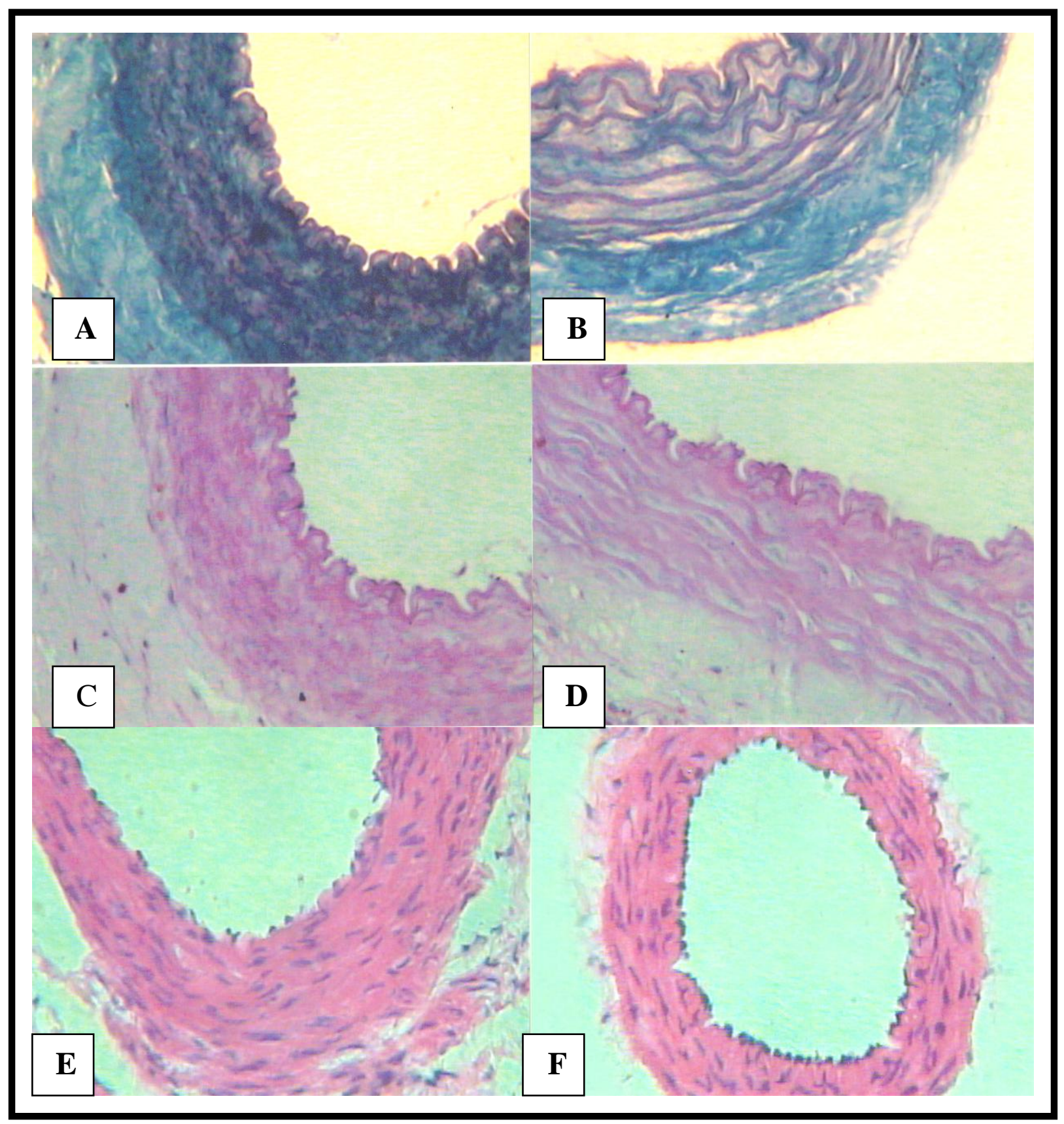

Plate 4 


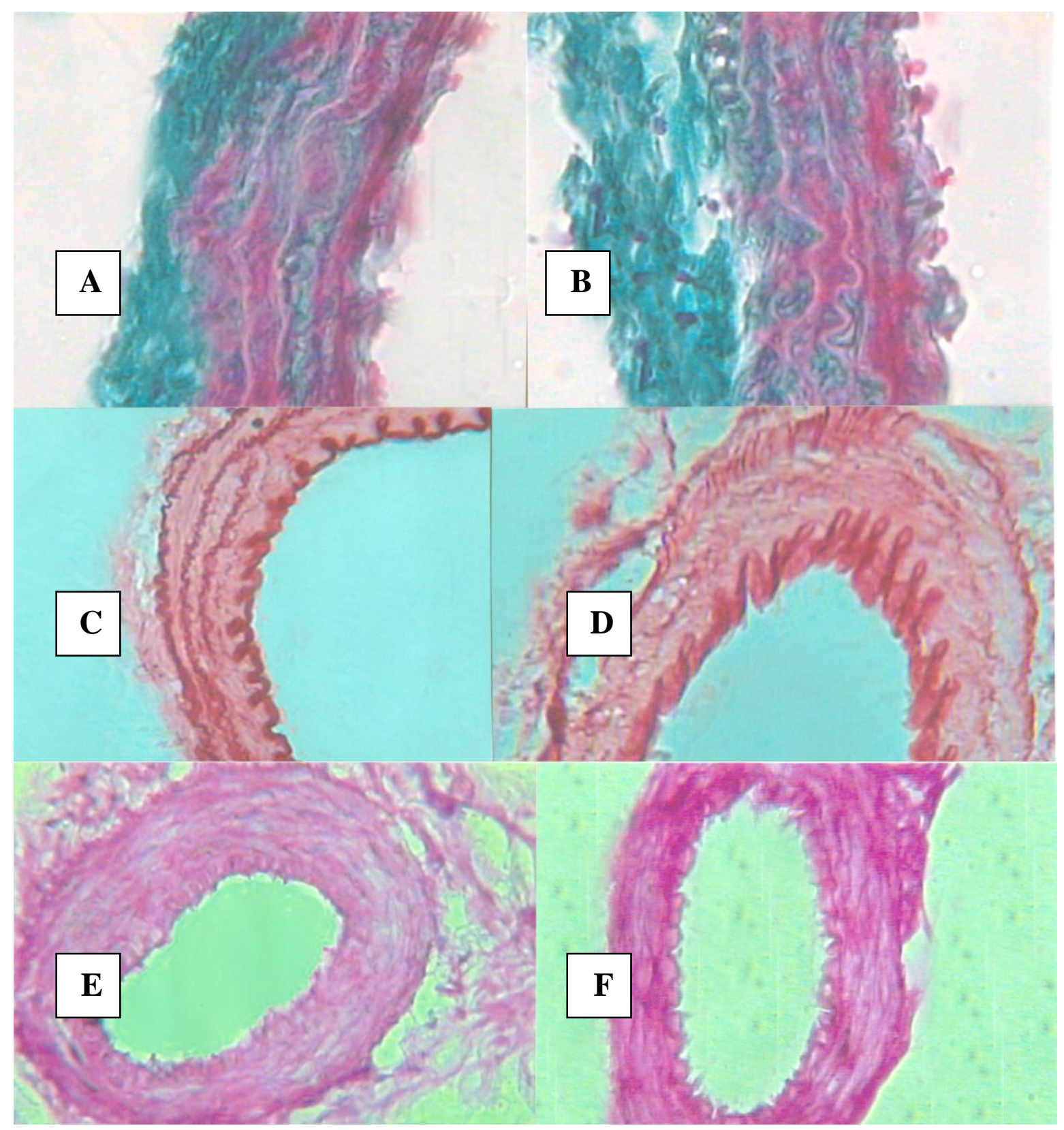

\section{Plate 5}

\section{Discussion}

Complications of atherosclerosis in patients with diabetes mellitus directed many studies to be focused on the disease(King, et al., 2002 ). However experimental approaches that can be made on human patients are limited because of difficulty in control, slow rate of lesion development, and the inability to make quantitative antemo rtum determinations of extent and severity of atheroscerotic lesions. 
Rabbits have been widely used as a model for atherosclerosis, but their use was restricted because the high mortality from Alloxan. In this study the Albino rats were used. They are considered to be the best animal model for chemical induction of diabetes mellitus(Silvio, 2003 ).

In this study the morphological changes which observed in the form of intimal thickining, migration and proliferation of smooth muscles, intracellular lipid accumulation, fragm entation of elastic fibers and increase in collagen was in agreement with (Robbins, 1990). Poulter, (1999) and Askari, et al., (2002) suggested that, migration and proliferation of smooth muscle cells from the tunica media to the tunica intima and the parallel increase in collagen synthesis in diabetic blood vessels was due to platelet derived growth factors (PDGF) present in diabetic environment or released from injured endothelial cells and membrane attack complex (MAC). These growth factors was reported to stimulate stimulate smooth muscle cell migration and proliferation (Acosta, et al., 2000).

The aorta of diabetic rats showed marked irregularity and fragmentation of elastic fibers. These changes had been explained by decreased elastin synthesis by smooth muscle cells as a results of oxidative damage (Guido\&Isabelle, 1996) or due to the increased activity of matrix metallop rotinases from the vascular endothelium as well as oxidative stress that breaking down collagen and elastin (Uemura, et al., 2001).

The increased amount of glycosaminoglycans in the matrix in aortic wall of diabetic rat could be related to the increased glycosamino glycans and proteoglycans synthesized by the proliferated arterial smooth muscle cells in early atheroscerotic lesions (Ttsuya, et al., 1994). Also glycosylation of the matrix component and the subsequent greate turnover of heparan sulfate(HS) was thought to stimulate a compensatory overproduc tion of other matrix components through altereation of growth regulatory factors between the matrix and cells. (Brownlee, et al., 1988)

The accumulated lipid seen in the aorta of diabetic group in our study, represented the foam cells. These cells were the macrophages and smooth muscle cells which absorbed lipid and their cytoplasm became swollen with (Roderick, \& Keith, 2001).

Lipids are either low density lipoproteins(LDL) particles that have been oxidized by the endothelium (Steinberg, 1988) or by smooth muscle cells and macrophages (Witztum, 1993). lipid Oxidation enhances its uptake by aortic intimal cells and monocyte-derived macrophages with stimulation of foam cells formation (Bucala, et al., 1993).

The increased ability of cells to oxidize LDL in the presence of high glucose concentration in diabetic patients, could play a significant role in the development of atherosclerosis (Daniel, et al., 2003).

The histological changes observed in the femoral artery of diabetic rats had been reported as atheroscerotic changes by (Poulter, 1999); (Acosta, et al., 2000) and (Daniel, et al., 2003).

Unlike the aorta, the renal arteries of diabetic rats showed minimal histolo gical changes by light microscopic examination, Our results was in accor dance with (Bakris, et al., 2000) and (Hovind, et al., 2001).

In conclusion, induction of diabetes in Albino rats was successful to produce vascular changes which was similar to that occurs in human to a 
great extent. These observed histology cal changes in blood vessels (abdominal aorta \& femoral arteries) of diabetic rats,are related to atheroscerotic changes.

\section{References}

1. Acosta, J, Hettinga, J, Fluckiger, R, Krumrei, N, Goldfine, A, Angarita, L, \& Halperin, J, (2000): Molecular basis for a link between complement and the vascular complications of diabetes. Proc Natl Acad Sci USA, 97:5450-5455.

2. Askari, C.B. Renard M. and Bornfeld, K.E. (2002) : Regulation of smooth muscle cell accumulation in diabetic-accelerated atherosclerosis. Histol and Histopathol. Univer. Washin. U.S.A.;17;1317-1328.

3. Bakris GL, Williams $M$, and Dworkin L. (2000): Preserving renal unction in adults with hypertention and diabetes: A consensus approach. Am J Kidney Dis; 36:646.

4. Brownlee, M, Cerami, A, \& Vlassara, H, (1988): Advanced glycosylation end products in tissue and the biochemical basis of diabetic complications. N Engl J Med, 318:1315-132.

5. Bucala, R, Makita, Z, Vega, G, Grundy, S, Koschinsky, T, Cerami, A, \& Vlassara, H, (1993): Modification of low density lipoprotein by advanced glycation end products contributes to the dyslipidemia of diabetes and renal insufficiency. Proc Natl Acad Sci USA, 91:9441-9445.

6. Danial Porte, Jr., Robert S.,Alain Baron, (2003): Diabetes Mellitus. Ellenberg Rifkin's. Sixth Edition. Mc Graw-Hell Comp, In. U.S.A. 11:1651700.

7. Dowens JG, Clearified M, Weis $\mathbf{S}$, et al, (1998): Primary prevention of acute coronary events with lovastatin in men and women with average cholesterol levels. JAMA ;279:1615.

8. Guido M., Isabelle J. (1996): Cells, Tissues, and Disease: Principles of general pathology. Printed in U.S.A.
Printed and bound by Braun-Brum field, Inc. : 30-33.

9. Hovind p, Rossing $\mathbf{P}$, Tarnow $\mathbf{L}$ (2001): Progression of diabetes nephropathy, kidney Int; 59:702.

10. King H, Aubert RE, Herman WH, (2002): Global burden of diabetes. 1995-2025: Prevalence, numerical estimates, and projections. Diabetes Care ; 21:14140.

11. Poulter N. (1999): The impact micronized fenofibrate on lipid sub fractions and on reaching HDL-target levels in 7,098 patients with dyslipidemia. The British J. of cardiology volume 6 issue 12:682-685.

12. Robbins, C.K. (1990): Pathologic basis of disease: Saunders Interna tional Edition. 11;543:551.

13. Roderick NM, and Keith W (2001): Textbook of pathology, Thirteen Edition, Oxford University Press, Inc., U.S.A. ; 12; 441:451.

14. Ross R. (1999): Atherosclerosis: an inflammatory disease. N Engl. J. Med. 340:115-126.

15. Silvio, JK.(2003): Diabetes Mellitus. Ellenberg Rifkin's. Sixth Edition. Mc Graw-Hell Comp, In. U.S.A .11: 1651700.

16. Steinberg D. (1988): Lipoproteins and atherosclerosis. A look back and a look a head. Atherosclerosis.3:283-301.

17. Sternby NH, (1968): Atherosclerosis and diabetes mellitus. Acta Pathol Microbial Scand ;194:152.

18. Tatsuya T., Masahiro M., Keiji S., Tsuneo I. (1994): Novel monoclonal antibody (ASH Ia / 256 C) recognizing a sialo GM-2 developed on the surface of fatty streak of atherosclerotic aorta. Elsevier Science B.V. 30: 225-259.

19. Uemura S, Matsushita H, Liw, Glassford AJ, Asagami T, Lee KH, DG, Tsao PS, (2001) : Diabetes mellitus enhances vascular matrixe metalloproteinase activity: Role of oxideative stress. Circ Res Jun 22;88(12):1291-1298.

20. Witztum J.L., (1993): Role of oxidized low density lipoprotein in atherogenesis. Br. Heart J. 69:S12S18. 


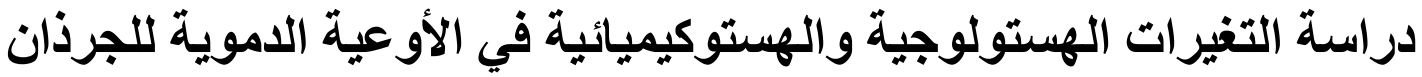

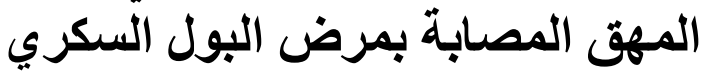

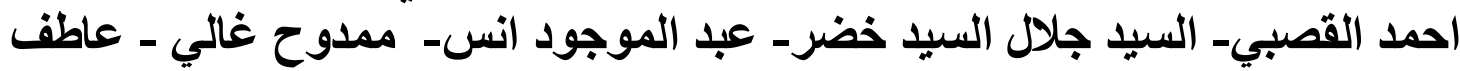

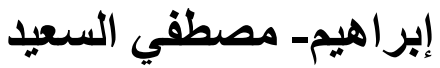 قسم الهستولوجيا بكلية الطب بنين جامعة الأزهر المبلد بالقاهرة}

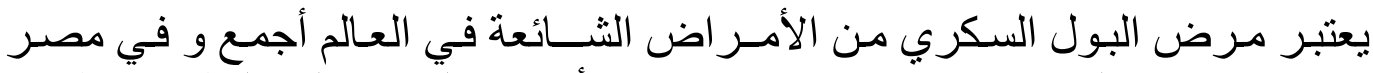

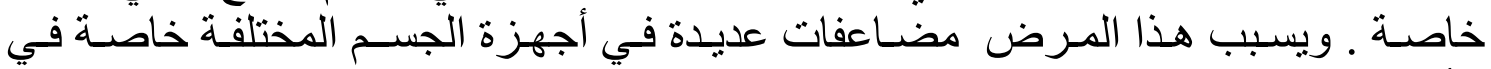

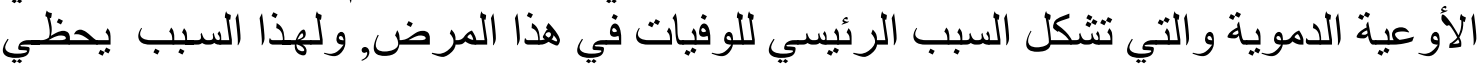

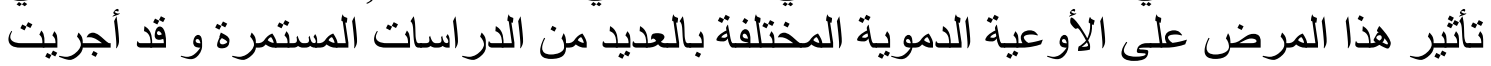

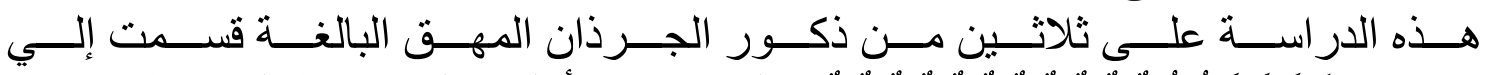

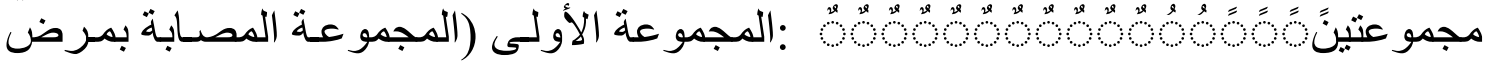

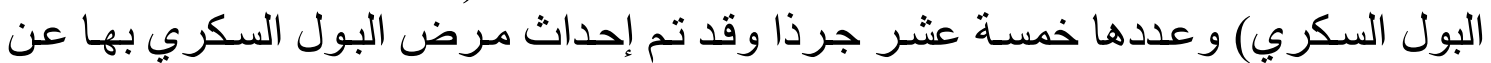

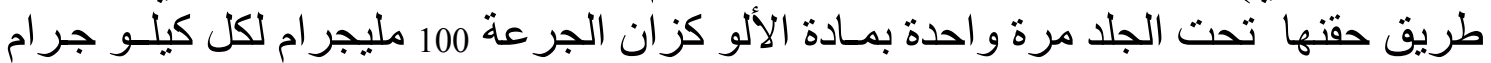

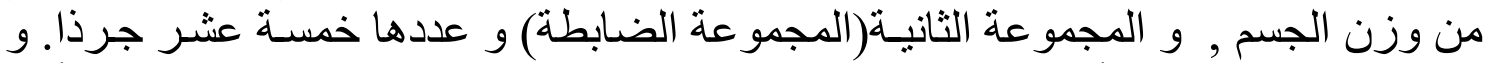

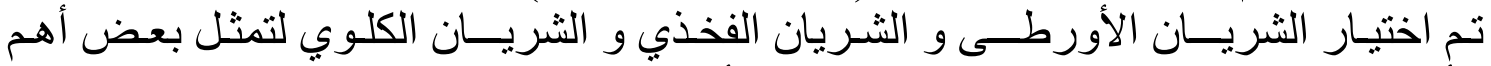

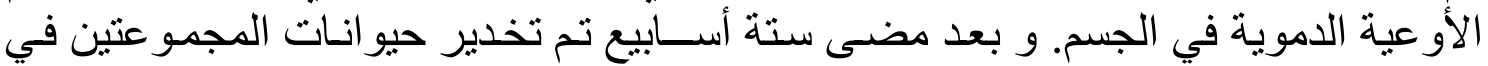

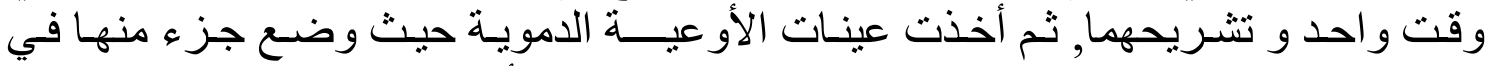

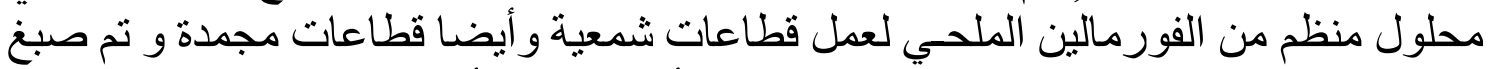

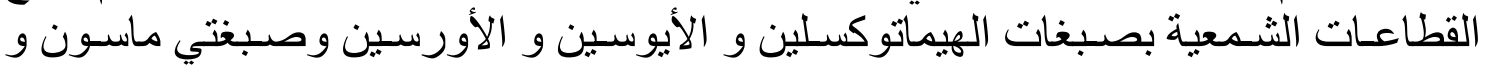

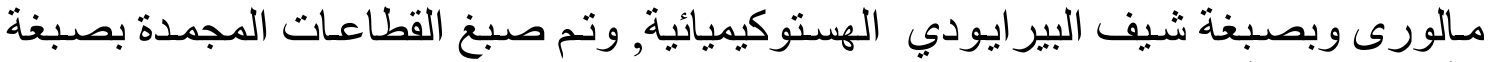

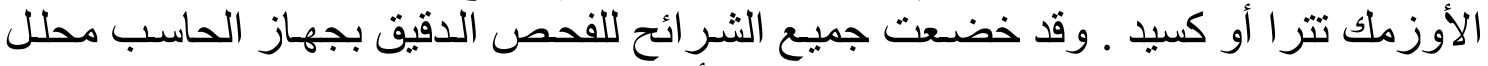

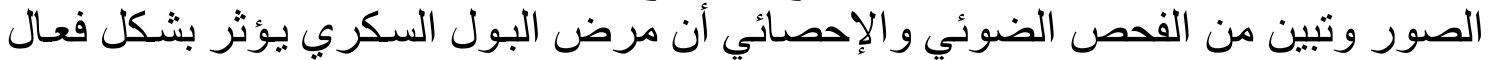

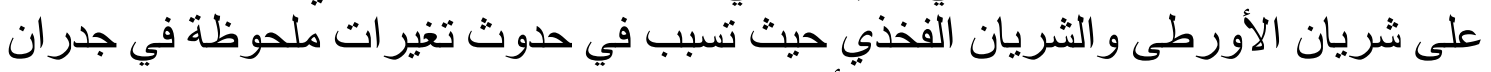

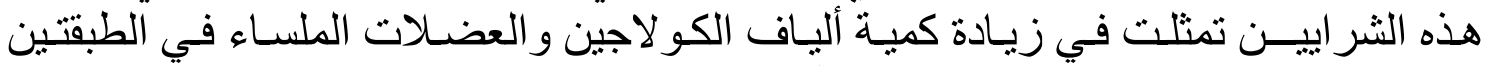

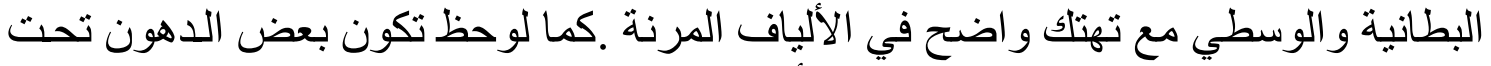

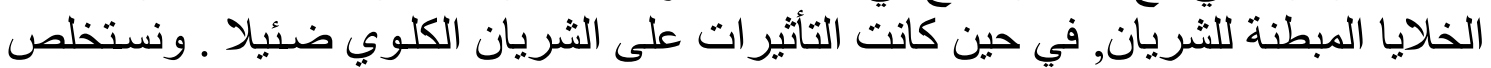

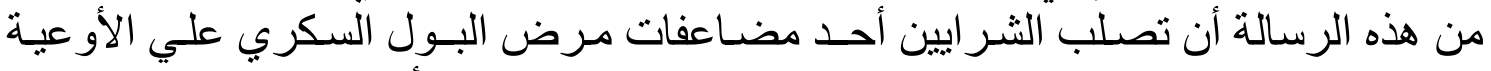

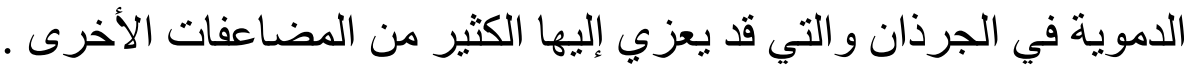

